\title{
PLANOS FUNDAMENTAIS DA ATMOSFERA DO ESCRAVOS DA MAUÁ
}

\author{
Caroline Peres Couto ${ }^{1}$
}

\section{Resumo:}

Neste artigo, investigo aspectos afetivos, estéticos e históricos que compunham, na roda de samba do Escravos da Mauá, um "clima”, uma atmosfera aprazível, segundo seus frequentadores. Tendo em vista que lugares, encontros entre pessoas, canções e paisagens podem despertar sensações corporais e produzir sentimentos singulares, questiono em que medida a produção de significados afetivos sobre os espaços públicos, e em determinados espaços públicos, interferem em suas formas de ocupação por parte da população.

Palavras-Chave: clima, atmosfera, espaço público, paisagem, região portuária.

\section{Abstract:}

This article treats the affective, aesthetic and historical aspects that composed, in the samba group of Escravos da Mauá, a "climate", a pleasant atmosphere according to their followers. Considering that places, encounters between people, songs and landscapes can arouse bodily sensations and produce singular feelings, it is important to question the extent to which the production of affective meanings related to public spaces and in certain public spaces interfere in their forms of occupation by part of the population.

Keywords: climate, atmosphere, public space, landscape, port region.

\footnotetext{
${ }^{1}$ Doutoranda pelo Programa de Pós-Graduação em Ciências Sociais (PPCIS) da Universidade Estadual do Rio de Janeiro (Uerj) e mestre em antropologia pela Université de Montreal (UdeM), Canadá. Tem interesse por temas que envolvem cultura e política, consumo, performance e emoções. Publicou La culture comme ressource dans le Port de Rio de Janeiro: des groupes de samba et de carnaval au sein d'un processus de réaménagement urbain (Éditions Universitaires Européennes, 2015).
} 


\section{Introdução}

Apresento neste trabalho algumas teorias e dados de campo que orientam minha hipótese sobre a emergência de uma atmosfera $^{2}$ (GRIFFERO, 2010) relacionada à Região Portuária do Rio de Janeiro, especificamente àquela experimentada pelo público cativo do bloco carnavalesco Escravos da Mauá, o chamado pedaço-da-Mauá (COUTO, 2009), que frequenta o Largo do São Francisco da Prainha, no bairro da Saúde.

Meu objetivo é analisar, com mediação teórica das noções de habitar e fluxos materiais desenvolvidas pelo antropólogo Tim Ingold (2012), as formas de sociabilidade no espaço urgidas entre aqueles atores, seus relatos e sensações relacionados a um "clima" único ${ }^{3}$ no momento em que acontecem as rodas de samba do bloco. A emergência do "clima" será discutida com base nos argumentos de Tim Ingold (2000, 2012), e ampliada por meio da teoria do filósofo Tonino Griffero (2010) que a entende, mais precisamente, como a criação de uma atmosfera cuja estética refletiria as qualidades emocionais de um espaço vivido.

As questões que perseguimos são: quais condições são necessárias para que um evento, realizado num determinado espaço, provoque sensações corpóreas e sentimentos nas pessoas? Existiriam alguns planos indispensáveis, nesse processo? Quais seriam eles? Na tentativa de produzir explicações para a atmosfera sentida e relatada pelos frequentadores, vamos apresentar cinco planos que surgiram a partir da pesquisa de campo e que ajudam a iluminar como se dá este fenômeno.

A contribuição de Tim Ingold (2012) ao nosso trabalho será principalmente de trazer, por meio da noção de habitar e fluxos materiais, o corpo de volta à cena, ao criticar a falsa projeção de um intelecto descorporificado no processo de criação e construção humana, provocando a superação da dualidade objeto versus sujeito por meio da realização do habitar, no sentido do ser-no-mundo hideggeriano (INGOLD, 2000, p. 186).

Por sua vez, os argumentos do filósofo Tonino Griffero (2010) parecem fundamentais, por destacarem as experiências cinestésicas sentidas pelo corpo-próprio e experimentadas no espaço vivido, detalhando alguns dos funcionamentos possíveis da atmosfera. A ênfase dada

\footnotetext{
${ }^{2} \mathrm{O}$ termo atmosfera é, a rigor, usado conceitualmente por Tonino Griffero; mas tomarei, ao longo do texto, como sinônimo a palavras descritas por meus interlocutores de pesquisa (como "clima", "energia" etc). Portanto, opto por utilizar o termo atmosfera em itálico, e, em muitas ocasiões, adoto-o como um termo abrangente, incluindo as sensações experimentadas pelo público durante as rodas de samba do grupo Escravos da Mauá. Deste modo, pretendo provocar uma aproximação com o universo das expressões nativas - assinaladas pelo uso de aspas - e a análise conceitual proposta pelo filósofo.

${ }^{3} \mathrm{O}$ "clima" especial sentido no Largo São Francisco da Prainha me foi relatado por diversas vezes em conversas e entrevistas com frequentadores.
} 
por Griffero às emoções e sensações vividas no corpo num local e tempo específicos será o aporte necessário para criar a imagem de atmosfera que acreditamos ser sentida e relatada pelos frequentadores do Escravos da Mauá.

O diálogo entre Tim Ingold e Tonino Griffero irrompe do entendimento comum que dividem sobre a natureza intersticial justamente daquilo que pretendem delimitar e analisar: Griffero (2011, p. 128) diz que "a atmosfera é um entre biografia e o mundo de fato", que não sofre qualquer intervenção de um sujeito sintetizador, e Tim Ingold (2012, p. 38), ao defender o processo dos fluxos materiais, apoia-se na teoria de Deleuze e Guattari (2004), reforçando o sentido dado por eles às linhas de fuga, definidas em seu devir não pela conexão ou relação de dois pontos ou mais, mas por um entre, uma linha de fuga que corre perpendicular a ambos. Ao que me parece, esta aproximação não é meramente fortuita, pois Ingold e Griffero são influenciados pela ampliação do estudo da fenomenologia, de um lado, com influências claras de Merleau-Ponty (1962) e de Martin Heidegger (1971) para o caso de Ingold; e, de outro lado, por influências das discussões estabelecidas por Hermann Schmitz (2011) e Gernot Böhme $(1995)^{4}$, que levaram Griffero ao estudo da atmosferologia.

\section{O Escravos da Mauá e um outro olhar sobre o porto}

Os desfiles de carnaval e as rodas de samba mensais organizadas pelo Escravos da Mauá, que se iniciaram em 1993, ganharam maior notoriedade na virada dos anos 2000, quando passaram a atrair um público inédito para a região: 20 mil pessoas por desfile (no ano de 2007) e em torno de mil a duas mil, por roda. $\mathrm{O}$ reconhecimento de suas ações foi sinalizado por instituições reputadas, por políticos e também manifestado por setores da população. Em 2000, receberam o Prêmio Urbanidade, concedido pelo Instituto dos Arquitetos do Brasil (IAB-RJ), que distingue ações de preservação e revitalização do patrimônio histórico e cultural e para a ocupação criativa do espaço público da cidade. Em 2008, receberam das mãos do vereador Eliomar Coelho (do Partido Socialismo e Liberdade/PSOL) a Moção de Louvor pela Revitalização da Zona Portuária, destacando a iniciativa do Escravos da Mauá e confirmando as contribuições do bloco para a cidade, além da emergência de uma dinâmica urbana inteiramente nova. Ainda em 2006, foram escolhidos, em eleição popular on-line, pelo Jornal do Brasil, o melhor bloco do carnaval.

\footnotetext{
${ }^{4}$ Cabe ressaltar que estes autores têm sido considerados como precursores do campo da neofenomenologia, exemplificando como o campo da fenomenologia tem se expandido.
} 
Uma dinâmica urbana inédita emergiu, com promoções explícitas daquele espaço, propiciando uma mancha urbana (MAGNANI, 2001) que conectava alguns trajetos entre o centro comercial da cidade, o Largo do São Francisco da Prainha e seus arredores, no bairro da Saúde, onde o bloco se apresenta, e que se tornou rapidamente um ponto de referência para aqueles que ali circulam. Apesar de frequentadores usarem carros para realizar seus deslocamentos até o Largo, muitos trabalhadores e estudantes do Centro da cidade começaram a efetuar o trajeto a pé e, assim, a "descobrir" a região, atraídos pelo evento, promovido gratuitamente. Tendo como base as entrevistas realizadas no período de 2008 a 2009, constatei que o público do Escravos da Mauá sofreu uma mudança drástica de faixa etária ainda nos anos 2000. Inicialmente, seu evento atraía grupos de amigos dos músicos e trabalhadores locais, de idades entre 40 e 60 anos e, conforme seus eventos foram ganhando visibilidade, surgiu a chamada "garotada": jovens na faixa dos 20 aos 30 anos interessados no samba e num happy hour com os amigos, que demonstravam maior tendência a explorar a localidade a pé.

A experimentação de trajetos e a circulação pelos arredores, independente da faixa etária do público, parecem ter sido sempre estimuladas pelos organizadores do bloco. Não somente durante as rodas de samba, como também em sua página de internet, o Escravos da Mauá ressaltava o valor de alguns passeios locais, como a visitação da "mística" Pedra do Sal, que seria "um passeio imperdível para qualquer carioca que se preze". Conhecer a Região Portuária, segundo essa narrativa, é antes de tudo valorizar a história da cidade pelo prisma do porto como ponto de origem cultural, a matriz fundadora e catalisadora das identidades da população.

Contudo, a valorização histórica não produziria efeitos somente de ordem simbólica, pois se tornava bastante tangível o impacto econômico positivo que as atividades mensais do bloco Escravos da Mauá promoviam localmente. Em meados de 2007, por exemplo, em cada evento do Escravos da Mauá, os bares e estabelecimentos da região faturavam o equivalente à renda obtida em um mês de trabalho regular (BARROS \& COSTA, 2014, p. 292).

Para melhor entender a emergência dessa nova dinâmica urbana, vale considerarmos o contexto político e social no qual as atividades musicais do Escravos da Mauá despontam, ainda na década de 1990. Os fundadores do bloco alertavam para o fato de terem sido fortemente inspirados pelo projeto Sagas (abreviação dos bairros locais Saúde, Gamboa e Santo Cristo),

\footnotetext{
${ }^{5} \mathrm{O}$ argumento é do grupo dos Escravos da Mauá e retirado do site Escravos da Mauá, curiosamente também chamado de "Circuitos do Rio". Disponível em: $<$ http://www.escravosdamaua.com.br/circ_maua.htm $\geq$. Acesso em: 8 jan. 2008.
} 
destinado a promover uma conversão simbólica de parte da Zona Portuária em sítio histórico. Este projeto se insere no bojo de diversas outras propostas urbanistas que, desde o final dos anos 1970, buscavam, ainda que de maneira mais técnica do que prática, a valorização e preservação daqueles que eram considerados patrimônios da área portuária (GUIMARÃES, 2011, p. 24).

$\mathrm{Na}$ virada dos anos 2000, a região volta a ter destaque pelo anúncio do projeto urbanístico Porto do Rio, que possuía como marcos, principalmente, as grandiosas propostas de construção do Museu Guggenheim, da Vila Olímpica da Gamboa e da Cidade do Samba, sendo que somente as duas últimas idealizações foram inauguradas - respectivamente, em 2004 e 2006.

As manifestações de interesse, por parte do poder público, em promover melhorias na região provocavam geralmente um sentimento ambíguo nos moradores e trabalhadores locais, um misto de esperança e desconfiança, haja vista a quantidade de projetos voltados para o mesmo objetivo, que não saíram do plano da idealização. Por esta razão, me interessa particularmente a ocupação pública promovida pelo Escravos da Mauá, por anteceder as grandes intervenções urbanísticas que surgem a partir de 2009 com o Porto Maravilha, projeto que transformou em definitivo a região. Ocupar e promover um evento na rua, até aquele período, significava necessariamente não ser incentivado, patrocinado, tampouco alimentar expectativas de um dia obter algum apoio da prefeitura. A falta de apoio as suas atividades por parte do poder público foi, aliás, um fator que levou o bloco a interromper em alguns momentos suas atividades e, em outros, aventar a possibilidade de parar definitivamente. Apesar de haver um reconhecimento de setores da sociedade da importância da iniciativa tocada pelo Escravos da Mauá, o impacto de seus eventos, que até 2008 nunca contaram com uma infraestrutura concedida pela prefeitura - como banheiros químicos, controle de tráfego, iluminação, coleta de lixo, segurança etc. -, preocupava por demais os organizadores, incomodados com as consequências sociais e patrimoniais depois de um dia de evento. Contava-se muito com a sorte para que tudo transcorresse bem e, principalmente, confiava-se no "clima bom" que a roda costumava provocar, sinônimo, entre outros, de "paz".

Assim, reconhecendo que existe uma influência inegável dos projetos destinados à região, penso que estas iniciativas não explicam por si a motivação e a perpetuação de ações locais observadas em campo, sobretudo a emergência da atmosfera, questão que aqui analisamos. A pesquisa também alertou para uma mudança de perspectiva, sobre a região, que essa forma de ocupação favoreceu. Assim, de local percebido como degradado e perigoso, a 
região passou a ser representada, nos discursos dos frequentadores, de maneira positiva, como um local tranquilo, de possível trânsito e de relativa segurança para circulação e permanência, lugar de moradia e comércio. Muitos chegam a relatar afetividade e envolvimento para com o Largo da Prainha, descrito como um ambiente aprazível, de boa energia, acolhedor. Esse discurso mais efusivo é interessante, sobretudo, por reportar as referências sobre este afetar-se, deixando entrever algumas pistas de como ocorreu a transformação da imagem de um lugar inseguro, que gera tensão e medo, para a de um lugar convidativo, que favorece o relaxamento e a descontração. A pista mais interessante é entender o papel primordial que as emoções e as sociabilidades possuem na maneira como construímos nossas percepções sobre o mundo e, consequentemente, nossos interesses pessoais, preferências, inclinações.

Apesar da relevância do fenômeno em que o bloco se tornou com a ampliação do seu público e os impactos urbanos subsequentes, o ponto central que me parece relevante é justamente o grupo cativo de frequentadores que o Escravos da Mauá formou e conservou, o que chamo de pedaço da Mauá. A categoria pedaço é utilizada pelo antropólogo José Guilherme Magnani (1996) para designar um espaço intermediário entre o privado e o público, onde se reforçam os laços de sociabilidade entre pessoas que, em sua maioria, possuem a mesma procedência. O sentido de procedência aqui não se vincula, no entanto, necessariamente, a uma origem ou classe social comuns, mas a um ethos compartilhado pelo grupo: aqueles que formam o público mais restrito do Escravos da Mauá podem possuir certas semelhanças em seus hábitos culturais, a começar pelos lugares escolhidos para o lazer, o tipo de consumo, o gosto estético e até um posicionamento político próximo.

A concentração sobre este grupo de pessoas se deu quase de forma inevitável no processo da pesquisa, principalmente porque, para uma observação antropológica, eram mais perceptíveis as formas de habitar (INGOLD, 2012) que ali desenrolavam entre eles. Habitar significa ultrapassar a falsa dicotomia havida entre o espaço físico do Largo e os significados simbólicos produzidos sobre o porto e sua história; é jogar luz sobre o processo de formação simultâneo, inacabado, sempre em aberto, no qual nos reunimos e participamos com a "coisa na sua coisificação", para relembrar o argumento clássico de Martin Heidegger (1971 apud INGOLD, 2012, grifo meu). No sentido sustentado por Tim Ingold (2012), a noção de coisa pretende enfrentar a lógica do objeto como um fato consumado, possuidor de superfícies congeladas e separado do sujeito. Segundo Ingold, coisa ajuda a evitar a tentação de encontrar a fácil saída de descrever um objeto passivamente recebendo um manto de significados 
produzidos pelas pessoas e também a perspectiva inversa, de simplesmente descrever a vida social dos objetos, atribuindo materialidade a sua agência.

A minha percepção sobre as formas de habitar desenroladas no pedaço da Mauá (COUTO, 2009) teve como ponto de partida, inevitavelmente, a produção discursiva sobre os significados atribuídos ao porto, que reforça a já dita apreensão limitada que dá enfoque à maneira pela qual pessoas tecem um manto de significados com o qual recobririam os objetos. Segundo Ingold (2012, p. 37), ler a criatividade das pessoas por esse prisma consistiria em lêla "de trás para frente", começando pelo que seria visto como resultado, traçando uma sequência prévia até imaginar que se chega à mente criadora do agente. Por esta abordagem, observamos meramente aquilo que seria a forma final de um processo criativo, reforçando a crença nas etapas lógicas e causais do processo criador e perdendo de vista todos os fios "em movimento, em fluxo, em variação", que se agregam quando as coisas simplesmente "acontecem" (INGOLD, 2012, p. 29). Contudo, foi por meio das produções discursivas dos entrevistados que foi possível me reunir ao acontecimento das coisas ou, para parafrasear Malinowski (1922), aos "imponderáveis da vida real": foram os entrevistados que me alertaram sobre a "energia" do Largo da Prainha e como se sentiam bem no "clima" de um fazer entre amigos que o bloco do Escravos da Mauá favorecia.

De acordo com seus relatos, podemos afirmar que o primeiro plano fundamental do Escravos da Mauá ligaria o espaço físico a uma expectativa e/ou sensação da vida passada, do ancestral. O Largo e seus arredores são descritos recorrentemente como um espaço "místico", centro de irradiação de energia pela sua antiguidade, em função do acúmulo de história ali vivida e presenciada. Essa visão é o carro-chefe do bloco do Escravos da Mauá, cujos integrantes não dispensaram esforços para "resgatar" a história dos bairros portuários e valorizá-los como matriz da cidade e das peculiaridades de sua população. Estes esforços estão materializados principalmente nas mídias que produziram - um site e um CD-Rom - a partir da compilação de dados historiográficos e pesquisas especializadas sobre a região. Estas mídias lhes servem de recursos em sua prática instrutiva, pois sustentam a legitimidade do seu conhecimento histórico e a divulgação pública que fazem sobre o valor do patrimônio local. Esta valorização ajuda a provocar, em alguns frequentadores, o despertar de um outro olhar sobre o Porto, ao serem estimulados por um imaginário peculiar sobre esse passado.

Em um segundo plano, a atmosfera sentida no local pode também ser relacionada aos recorrentes encontros casuais e prazerosos entre amigos e conhecidos que a roda promove. 
Essa atmosfera pode ser mais bem sentida principalmente quando se está no pedaço da Mauá, preferencialmente de frente para a roda de samba ou em suas laterais (Figura 1).

Figura 1 - Mapa do Largo da Prainha com a organização promovida pelos músicos, vendedores e frequentadores em um dia de roda de samba dos Escravos da Mauá. O local ocupado pelos frequentadores pode também ser lido como o que chamamos de pedaço da Mauá.

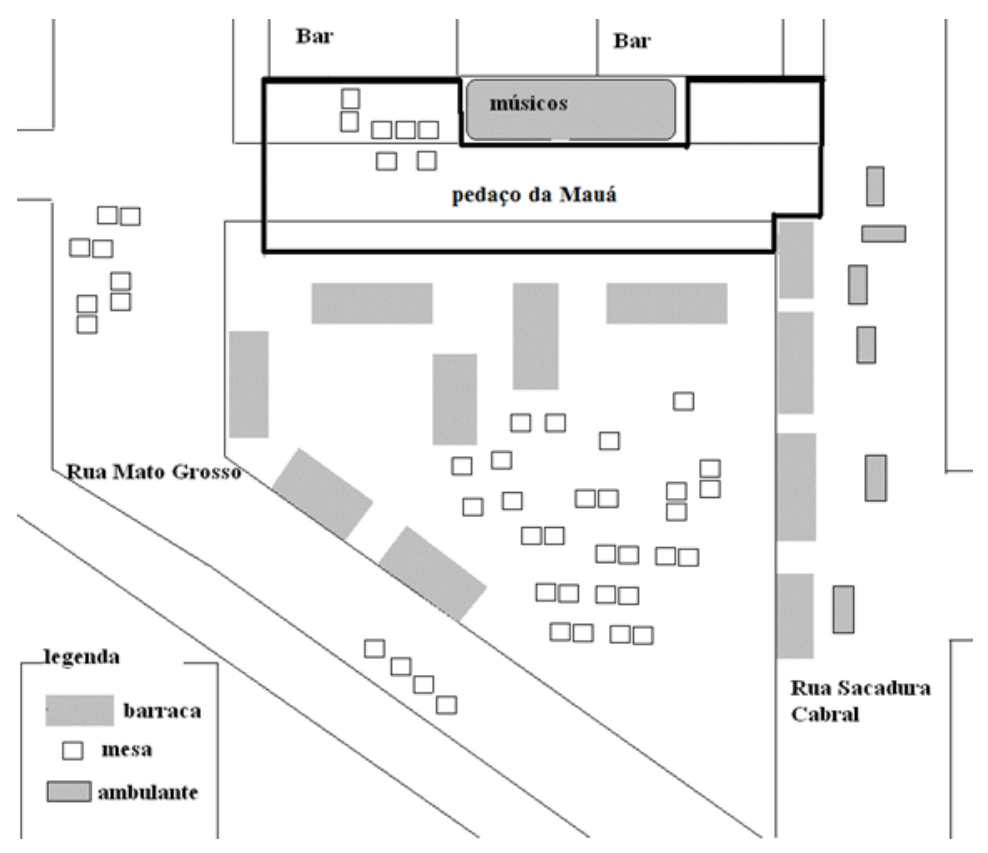

Fonte: arquivo pessoal.

O pedaço tornar-se um ponto de referência auxilia a "distinguir determinado grupo de frequentadores como pertencentes a uma rede de relações" (MAGNANI, 2008, p. 32). Aqueles que são do pedaço da Mauá relatam que reencontram, em diversos eventos pela cidade, muitas daquelas pessoas que vão com regularidade à roda de samba dos Escravos da Mauá, sinalizando um certo compartilhamento de preferências e gostos, entre eles. Alguns chegam a virar amigos "de frequentar a casa", outros são "amigos de samba no pé”, e também tem aqueles que se abraçam, beijam, mas nem se lembram (ou sabem) sequer dos nomes uns dos outros (COUTO, 2009).

Ao chegar no pedaço, o frequentador do Escravos da Mauá se sente "em casa", "à vontade" e, caso um amigo, colega ou conhecido introduza um novo frequentador no ambiente, este possivelmente será acolhido com boa vontade. Pois, como nos afirmou um entrevistado: 
levando a primeira vez e tal, é amigo também. Tipo assim, quem é da Mauá, ah, é da Mauá! Então é uma referência, gente boa. Se ela gosta dos Escravos é porque é gente boa (COUTO, 2009).

Contudo, como afirma Magnani (2008, p. 33), pertencer a essa rede implica o cumprimento de determinadas regras de lealdade que funcionam também como proteção. Observamos se desenvolver uma certa tensão, por exemplo, quando as rodas de samba começaram a encher com aqueles que são chamados, por quem é do pedaço, de "caras-semcamisa", identificados por um comportamento agressivo e inadequado, para as regras de convivência estabelecidas pelos do pedaço. Os "caras-sem-camisa" são vistos como atraídos pelo motivo "som, bebida e mulher", empurram o público do pedaço e o importuna com abordagens inconvenientes, bebem demais e usam drogas de forma pouco discreta, enfim, apresentam comportamentos que são vistos como ameaçadores para a continuidade das atividades da roda num "clima" positivo e tranquilo. Para os do pedaço, os "caras-sem-camisa" não são capazes de entender as regras de respeito por eles compartilhadas e muito menos "sabem onde estão", no sentido de apresentar respeito pelos frequentadores antigos, mas também pelos moradores e prezar pela conservação do patrimônio local (COUTO, 2009).

Num terceiro plano, não exatamente separado do "clima" do pedaço, temos a maneira ritualizada em que a roda de samba é apresentada. Pontuadas de brincadeiras, com um roteiro musical regular e reconhecido, danças debochadamente coreografadas, alcunhas dadas ao público pelos músicos (as "cabrochas" e a "rapaziada dos Escravos da Mauá") e uma série de gags vastamente conhecidas (e repetidas) pelo público (ente elas, uma debocha da rixa entre cariocas e paulistas em dias de tempo instáveis: “A chuva foi para São Paulo!”), as rodas favorecem uma sensação amistosa entre os frequentadores, que naquele momento se tornam brincantes e se sentem ainda mais à vontade na construção de uma rede de sociabilidade própria entre eles.

A ritualização da roda de samba do Escravos da Mauá traz consigo uma ação performativa (TAMBIAH, 1985 apud PEIRANO, 2003) que tanto mantém uma abertura para a improvisação como atinge uma eficácia no momento da sua realização, ao provocar reações naqueles frequentadores e fazê-los se sentir, entre diversas outras emoções, parte da cidade. Essa sensação é provocada principalmente na fase final da roda e também durante a execução de alguns sambas. Esta fase final, por sua vez, nos aproxima do quarto plano que forma a atmosfera percebida no Escravos da Mauá: quando são cantadas músicas relativas ao Rio de Janeiro, de conhecimento público (entre elas, "Saudades da Guanabara”, de Moacyr Luz, Paulo 
César Pinheiro e Aldir Blanc; "Samba do avião", de Tom Jobim; e "Aquele abraço", de Gilberto Gil) e outras, compostas pelos integrantes do bloco. As composições das letras dão destaque à desigualdade e à injustiça urbanas, mas também falam das belezas naturais e riquezas culturais do Rio. Esta seleção musical, feita para compor o grande final da roda parece orientada por um viés político, que defende um congraçamento de setores sociais e espaços conflagrados da cidade e reforça a necessidade da ocupação do espaço público por parte da população como forma de fazer frente à onda de terror quanto ao futuro do Rio de Janeiro, tal qual o bloco se propõe a fazer. "Acreditamos que, apesar de tudo, ainda é possível viver nessa cidade", falava emocionada, ao microfone, a cantora do bloco, ao final de uma roda de samba em um mês em que haviam sido mortos, na proximidade, três rapazes, moradores do Morro da Providência.

Os fundadores do bloco, hoje, num olhar retrospectivo sobre sua própria história, reforçam que teria sido justamente a violência dos anos 1990 e o movimento quase inexorável da privatização do espaço público na cidade, por esta época, que lhes impulsionaram a resistir e ocupar o espaço público, principalmente um local estigmatizado, como o Largo.

Num quinto plano da atmosfera, consideramos que a construção física do Largo exerce um papel fundamental para a criação deste "clima", o que é abertamente reconhecido e descrito pelos frequentadores. Em certa ocasião, alguns relataram que o Escravos da Mauá se apresentou num outro local enquanto o Largo passava por obras, porém o evento "não é a mesma coisa", pois a "energia" do Largo é que tornaria o evento especial (COUTO, 2009). Os casarios e a arquitetura antiga parecem ajudar a fazer sentir algo sobre aquele passado, mas também sobre o presente e o futuro que contam e planejam para a cidade e para si mesmos. Outros frequentadores lembram que, quando chegaram, pela primeira vez, ao local para a roda de samba, os amigos faziam questão de lhes apresentar a história local que aprenderam com o bloco, levando o outro a imaginar como seria "na época dos escravos", ou quando "ainda havia o mar, a prainha" antes de aterrados, com os casarões amplamente ocupados, pessoas circulando a pé, de bonde, em charretes, a venda de sal... em sobreposições de tempos passados, por eles projetados. A ideia do Porto como porta de entrada da cidade, pelo mar, é fortemente desenvolvida e até mesmo visualizada por quem passa a compartilhar desse conjunto de informações sobre a história da cidade.

Figura 2 - Largo da Prainha numa sexta-feira à tarde, ainda nos preparativos para uma roda do Escravos da Mauá. Rio de Janeiro, 22 de maio de 2009. 


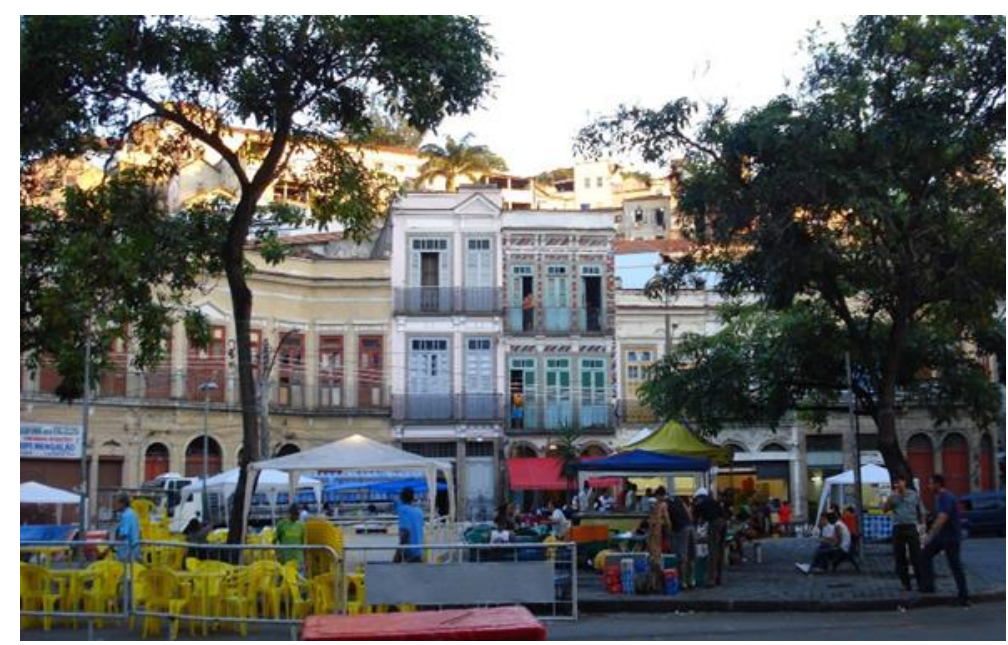

Fonte: arquivo pessoal.

Este imaginário construído sobre a localidade e sobre a cidade como um todo reforça uma sensação de pertencimento que pode ser experimentada por alguns com bastante intensidade, de se estar ali, onde tantos ancestrais teriam se erguido sob as "pedras pisadas do cais" que o bloco do Escravos da Mauá repetidamente canta na música $O$ mestre-sala dos mares (Aldir Blanc/João Bosco).

Estimulada pelas ideias de Griffero (2010), considero relevante também dar destaque aos aspectos do tempo e espaço que são vivenciados pelos frequentadores, que não surgem necessariamente em seus discursos. Por exemplo, o fato de a roda acontecer numa sexta-feira à noite, num horário pré-determinado, possivelmente conta para o estabelecimento de um "clima" que o público diz vivenciar. A iluminação noturna, os arranjos de ocupação feitos ao longo do Largo e aquilo que é possível ver, contemplar e sentir de um dado ponto de vista, tudo isso influi na fruição estética e na constituição emocional do Largo da Prainha enquanto atmosfera. Esse último plano é certamente tributário, em grande parte, da construção ocidental da paisagem (CAUQUELIN, 2011), que busca ordenar, por meio da perspectiva artística, uma "harmonia emoldurada" da natureza física, mas também da cultura humana. A princípio, essa lógica cognitiva sobre paisagem reforça uma preexistência daquilo que deve ser visto, imprimindo uma emoção estética por filtros simbólicos que dão destaque a determinados aspectos, direcionando o olhar. Quando mobilizada pelas narrativas históricas, contudo, a paisagem não é meramente um invólucro da ação que nela transcorre, mas "nada é sem os corpos em ação que a ocupam" (CAUQUELIN, 2011, p. 49), o que nos permite depreender que os observadores do Largo da Prainha podem construir uma relação com o espaço pautada tanto pela perspectiva da paisagem, a "harmonia emoldurada", mas também por uma ação imaginativa provocada 
pelos encontros da roda de samba do Escravos da Mauá, fazendo do espaço algo construído pelos “corpos em ação", num tempo presente (CAUQUELIN, 2011, p. 49).

A percepção visual e imaginativa do espaço físico é uma das qualidades sensíveis consideradas também por Griffero (2010), mas não é a única e nem mesmo a determinante para entendermos a atmosfera do Largo da Prainha. Apesar disso, por destacar a percepção visual e suas sensações decorrentes, este quinto e último plano pode aproximar os outros planos anteriores e facilitar nosso entendimento sobre algumas das sensações sentidas e descritas pelos frequentadores.

\section{O "clima" de amizade e esperança de paz na cidade}

"No Rio a esperança não cansa jamais", canta o bloco em uma de suas músicas compostas para o carnaval ${ }^{6}$. O "clima de amizade e paz" experimentado pelo pedaço durante as rodas é cantado e exaltado também em outras letras, que parecem indicar que a panaceia para os agouros sociais seja a amizade, descrita como "o melhor remédio" para a tristeza e o desespero diante da violência e degradação urbana que faz querer "fugir daqui"”.

Aquilo que aparentemente poderia ser visto como um corriqueiro encontro de amigos e conhecidos num espaço público revela-se como forma de sinalizar identificações, pertencimentos, valores, gostos estéticos aproximados, além de uma forma de resistência política tácita frente à brutalidade experimentada diariamente pelos moradores da cidade. Ocupar o espaço público é desafiar o pessimismo em relação ao futuro da cidade, é comunicar a crença em uma convivência outra, pacífica, apesar de não sem conflitos, mas onde sejam favorecidos encontros plurais entre os habitantes da cidade. A amizade e as redes de sociabilidade tecidas nessas noites de samba, as brincadeiras, danças e outras particularidades da roda aproximam os corpos das pessoas, favorecem as relações amistosas, em que o beijar, abraçar ou sorrir para um desconhecido, em tempos de aridez social, é visto como um gesto prenunciado e bem acolhido entre os do pedaço.

Além disso, por ser permeado pelo lúdico, o ritual da roda de samba serve como um meio amigável, que convida a história de papel a entrar no corpo e fornecer contornos às identificações e memórias afetivas elaboradas para com o lugar. Como sugere o filósofo Paul Ricoeur (2000), é no plano intermediário ocupado pela philia que as lembranças individuais

\footnotetext{
${ }^{6}$ Parte da letra do samba "Boa Companhia Faz o Dia Clarear"' do ano de 2006.

${ }^{7}$ Respectivamente parte da letra do samba "Boa Companhia Faz o Dia Clarear" do ano de 2006 e do "Cidadania na Praça Mauá” de 1994.
} 
são transmitidas e difundidas como memória coletiva, tais quais, podemos acrescentar, os conhecimentos individuais de toda natureza, inclusive históricos. Ou seja, mais que a divulgação formal dos eventos históricos, é no boca a boca que aprendemos e apreendemos, de maneira afetiva, alguns conteúdos. O processo cognitivo não conta meramente com o processamento de informações por um fluxo racional, mas também e principalmente pelo emocional.

Em consonância com os argumentos de Tim Ingold (2012), que critica a dicotomia do modelo hilemórfico aristotélico, segundo o qual de um lado se tem a materialidade bruta (hyle), de outro a ação dos seres humanos que lhes dão forma e significado (morphé), acentuo também o desejo de superação da dicotomia razão e emoção, para explicar a ação humana. Seja pela entrada da emoção ou da razão, parece-me que geralmente estamos em nossas análises fazendo o chamado processo de abdução (INGOLD, 2012), ou seja, seguindo a criatividade humana de trás para frente, partindo do resultado até a mente que o arquitetou. Abandonar tais dicotomias permitem uma circulação mais livre nos ares da atmosfera de Griffero (2010, p. 9), que nos alerta, no entanto, para a impossibilidade de penetrá-la por completo, pela sua inescapável imprecisão semântica e pela natureza fugidia, incabível em uma ontologia tradicional. A atmosfera não se enverga à objetividade. Seria justamente o sentimento que encontra seu espaço no exterior e anima nossa presença no mundo, ou, para reforçar a linha teórica já desenvolvida, anima o nosso habitar, no sentido dado por Ingold (2012).

O significado atmosférico, segundo Griffero (2010), seria expresso no nível de qualidades sensíveis e é imanente ao objeto; ele não é adicionado cognitivamente em um momento posterior à percepção da cena, mas sim precede e dirige-se à percepção (CALONI, 2012, p. 123-124). Atmosfera seria uma "superestrutura emergente" (GRIFFERO, 2010, p. 59) a partir das coisas que é capaz de animar: em última análise, é um agregado de sentido, linhas de força autônomas, que se mostra através dos objetos que se combinam para estabelecê-la. Griffero (2010) insiste que a atmosfera não é uma transferência ao externo dos sentimentos subjetivos, mas qualidades externas de significado irredutível e autônomo, que pode incentivar determinados sentimentos subjetivos mas que são configuradas independentemente deles.

O acento sobre a imanência do objeto alinha-se à lógica dos fluxos materiais de Ingold (2000, 2012), que esclarece que:

[...] people do not import their ideas, plans or mental representations into the world, since the very world, to borrow a phrase from Merleau-Ponty (1962: 24), is the homeland of their thoughts. Only because they already dwell therein can they think the thoughts they do (INGOLD, 2000, p. 186). 
O mundo é o próprio local de nascimento (homeland) dos nossos pensamentos e toda ação humana é precedida e orientada pelo ser-no-mundo, pelo habitar. Os fluxos materiais se emaranham sem seguir uma ordem determinada ou conexão prévia, assim como na definição de atmosfera de Griffero (2010), que é percebida por meio das cinestesias corporais, mas existe sempre fora do corpo e não pode se constranger pela ação de um sujeito sintetizador. Talvez por isso Griffero (2010) sugira uma provocação que propõe ampliar ainda mais a noção de coisa hideggeriana: a quase-coisa, mais turva, amorfa e aberta ontologicamente.

Finalmente, de acordo com Griffero (2010), a qualidade mais notável que pode ser inferida da atmosfera é a obviedade de sua existência, perceptível e descritível a qualquer pessoa. E isso significa dizer que, quando aparece descrita no discurso, ressaltando emoções relacionadas a um "clima" de um lugar ou de um objeto, a atmosfera não diz respeito a um simples recurso metafórico. A recorrência do apelo à noção de atmosfera, "clima" e às sensações nos discursos cotidianos das pessoas seria aquilo que confirma a existência da atmosfera e provoca a superação da dualidade literal/figurativo, não precisando ser questionada a linguagem que é repetidamente usada para descrevê-la. Pelo que sugere Griffero (2010), não há nada por detrás na atmosfera, mas um entre. Neste sentido, aproxima-se a natureza intersticial da atmosfera à noção de habitar: o que importa para Ingold (2000) e Griffero (2010) não são as relações, conexões, etapas de um processo, mas as linhas de fuga, aquilo que corre em perpendicular no processo emaranhado das coisas quando em vida. Daí a impossibilidade de penetrarmos completamente, por um esforço objetivo, na atmosfera.

\section{Conclusão}

As teorias filosóficas apresentadas nesse trabalho associadas aos dados de campo nos ajudam a sustentar que a atmosfera experimentada e descrita pelos frequentadores do Escravos da Mauá não pode ser meramente compreendida como resultado de uma intencionalidade arquitetada pelos organizadores do bloco, mesmo que estes tenham se empenhado em cumprir papéis engajados em valorizar e divulgar a região. Nem mesmo que seja uma consequência inevitável do empenho público de valorização do patrimônio físico, apesar de ajudarem a entender algumas questões que estivessem em jogo naquele momento e também facilitar a montagem de um pano de fundo para os acontecimentos acompanhados. Concluo que seria inconveniente nos apoiarmos numa lógica que aponte para uma explicação enquanto um mero somatório dos acontecimentos e ações, apesar de reconhecer que há, num certo nível, influências entre certos eventos. Mesmo a distinção inicial que me proponho a fazer - separando 
o fenômeno de público do Escravos da Mauá com o afeto relatado pelos do pedaço - poderia, num outro momento, ser desfeita, pois talvez sejam acontecimentos tão díspares, como inicialmente avaliados, mas que mantenham uma proximidade e tenham mais a dizer um sobre o outro.

Como sustenta Tim Ingold (2012, p. 27), devemos substituir o modelo hilemórfico por uma ontologia "que dê primazia aos processos de formação ao invés do produto final, e aos fluxos e transformações dos materiais ao invés dos estados da matéria”. Citando o pintor Paul Klee, Ingold lembra que a forma acabada é morte, mas o processo de dar forma é vida.

Apesar disto, apresentei, numa segmentação analítica, os planos que consegui depreender da pesquisa e que considero relevantes para uma melhor compreensão do todo que acontece no Escravos da Mauá, mesmo que eles não deem conta do que acontece em perpendicular a eles, para lembrar a imagem das linhas de fuga. O primeiro plano foi aquele da divulgação histórica; o segundo, dos encontros casuais que acontecem durante o evento; no terceiro, dei destaque à ritualização da roda de samba e suas brincadeiras; no quarto, aparece a relação entre ocupação do Largo e superação dos problemas da cidade; e o quinto tem por tentativa, por meio do destaque dado ao visual, aproximar as cinestesias provocadas pelos outros planos em conjunto.

Os planos dão algumas pistas sobre a atmosfera criada durante as rodas e nos ajudam a buscar escapar de conclusões baseadas no modelo hilemórfico, segundo as quais ou bem as pessoas vão àquele lugar, aprendem sobre sua história, tecem e jogam sobre a espacialidade seu manto simbólico ou bem o lugar tem em si uma potência capaz de transformar suas percepções, de forma independente.

A atmosfera do Escravos da Mauá é vivida e percebida pelas pessoas, faz sentido para elas ao estarem lá. A contribuição que nesta pesquisa me proponho a fazer é mais do que indicar aquilo que estaria sendo dito por meio da amizade ou do reconhecimento do "clima" local; talvez a atenção devesse se deslocar para como estes encontros acontecem e principalmente para o "clima" de relaxamento ("decorporazione", nos termos de Griffero, 2010) experimentado pelos frequentadores. Talvez, a partir disto, sejamos capazes de entender alguns detalhes de como se processa a transformação da dinâmica urbana e dos significados (em termos muito mais amplos) atribuídos àquele espaço. A polarização emocional com o qual o espaço analisado pode ser descrito - indo da tensão ao relaxamento, do perigo ao acolhimento - pode indicar uma reversão interessante a ser considerada para entendermos como se dão os processos de mudanças que ocorrem no Largo e também em outros espaços da cidade. 


\section{Referências bibliográficas}

BARROS, Maria Teresa Guilhon \& COSTA, Ricardo Sacramento. "Redes de afeto e pertencimento no carnaval de rua da região portuária carioca". In: De baixo para Cima. Rio de Janeiro: Editora Aeroplano, 2014.

BÖHME, Gernot. Atmosphäre. Essays zur neuen Ästhetik. Frankfurt a. M: Suhrkamp, 1995.

CALONI, Paolo. "Recensione di Atmosferologia. Estetica degli spazi emozionali". Methode Analytic Perspectives, Vol 1, No 1 (2012): Art, Objects, 2012.

CAUQUELIN, Anne. “As formas de uma gênese”. In: A Invenção da Paisagem. São Paulo: Martins Fontes, 2011. pp. 33-100.

COUTO, Caroline P. E o samba serpenteia pelas ruas da Mauá: os Escravos da Mauá e a revalorização cultural espontânea da região portuária do Rio de Janeiro. Rio de Janeiro: UFF/ Biblioteca Central do Gragoatá. 145 páginas, 2009.

GRIFFERO, Tonino, Atmosferologia. Estetica degli spazi emozionali Roma-Bari, Laterza, 2010.

GUIMARÃES, Roberta Sampaio. “Introdução: a 'revitalização' da Zona Portuária e seus efeitos”. In: A utopia da Pequena África: Os espaços do patrimônio na Zona Portuária carioca. Tese de Doutorado apresentada ao Programa de Pós-Graduação em Sociologia e Antropologia / Instituto de Filosofia e Ciências Sociais da Universidade Federal do Rio de Janeiro, 2011.

HEIDEGGER, Martin. Poetry, language, thought. Trans. A Hofstadter. New York: Harper \& Row, 1971.

INGOLD, Tim. "Trazendo as coisas de volta à vida: emaranhados criativos num mundo de materiais". Horizontes antropológicos, 201218 (37): 25-44.

INGOLD, Tim. "Building, dwelling, living: how animals and people make themselves at home in the world. In: The perception of the environment: essays in livelihood, dwelling and skill. London: Routledge, 2000. Pp. 172-188.

MAGNANI, José Guilherme. "Quando o campo é a cidade: fazendo antropologia na metrópole”. In: Na Metrópole. São Paulo: Edusp.2008. pp. 12-53.

MERLEAU-PONTY, Maurice. Phenomenology of Perception, Trans. C. Smith (New York: The Humanities Press, 1962.

PEIRANO, Mariza. "Rituais: ontem e hoje”. In: Ciências Sociais Passo-a-passo, no 24, Rio de Janeiro: Jorge Zahar, 2003.

RICOEUR, Paul. La mémoire, l'histoire, l'oubli. Paris : Seuil, 2000.

SCHMITZ, Hermann. Nuova Fenomenologia. Una introduzione. Ed. by T. Griffero. Milano: Marinotti, 2011. 
Recebido em: Julho de 2016 Aprovado em: Outubro de 2017 